\title{
LA FALTA DE CONFORMIDAD EN LA NUEVA LEY DE GARANTIAS EN LA VENTA DE BIENES DE CONSUMO
}

\author{
Dr. D. Emilio González Bilbao \\ Profesor de Derecho mercantil \\ Universidad de Deusto
}

Sumario: 1. Contextualización de la nueva Ley. 2. Introducción. 3. Bienes de consumo. 4. Concepto de consumidor en la nueva Ley. 5. La conformidad de los bienes con el contrato. 5.1. Principio de conformidad. 5.2. Requisitos de conformidad. 6. Derechos del consumidor ante una falta de conformidad. 6.1. Sistema de primera opción de saneamiento y posterior de reducción de precio o resolución. 6.2. Limitaciones a la opción de saneamiento. 6.3. Reglas y condiciones de saneamiento. 7. Nuevo sistema de plazos. Recapitulación.

\section{Objetivo del presente trabajo}

Se desea perfilar el «marco de conflicto» del cual derivan los derechos de los consumidores en la nueva Ley de Garantías en la Venta de Bienes de Consumo, Ley 23/2003 de 10 de Julio (BOE de 11.07.03) en adelante LGVBC o Ley de Garantías. Se dice «marco de conflicto» porque los defectos, el mal funcionamiento y los vicios ocultos generan una falta de conformidad a partir de la cual se constituyen los derechos de los consumidores.

A tal fin, se desarrolla un apartado de caracterización del consumidor y después el análisis de la falta de conformidad y plazos de cobertura legal para los consumidores. Conviene realizar una contextualización previa que nos ayudará a comprender la finalidad de esta ley y el efecto de saneamiento de los circuitos comerciales que procura. Conviene destacar, ya desde ahora, la existencia de un triple régimen de saneamiento por vicios ocultos relativo al ámbito mercantil, otro al civil y uno más específico respecto de la venta de bienes de consumo que se regula en esta Ley.

\section{Contextualización de la nueva Ley}

Se señalan a continuación algunas reflexiones sobre el origen de la nueva regulación, la necesidad social de su consideración y los efectos de mercado que se pueden derivar. También se medita sobre el uso de 
técnicas de gestión alternativa de conflictos, al margen del procedimiento judicial.

- Coste de acceso a Tribunales: Cualquier persona, física o jurídica, puede ejercer sus derechos ante los Tribunales mediante el ejercicio de las acciones correspondientes. Sin embargo, en ocasiones, cuando se trata de cuestiones de escasa cuantía, se vuelve difícil por no decir imposible la reclamación. Ello deriva del mayor costo de reclamación que la reparación o saneamiento del bien adquirido. Muchas empresas ante cuestiones pequeñas, optan por no reclamar y asumir el costo de este perjuicio derivado de una deficiencia del bien adquirido. En reclamaciones pequeñas, se rechaza acudir a la reclamación judicial.

- Plazos cortos de reclamación: además, los plazos para el saneamiento por vicios ocultos son breves $\mathrm{y}$, pasados éstos, por ser de caducidad, se perjudican las acciones. Sin embargo, los bienes que se adquieren muchas veces están aparentemente correctos pero luego, en su uso, presentan patologías que indican la existencia de una falta de conformidad del bien con el contrato de adquisición. Sin embargo, ya no existe posibilidad de reclamación alguna, por la existencia de plazos cortos y de caducidad.

- Reclamación más difícil para consumidor: los consumidores están sujetos a estos mismos plazos, pero además con el agravante de no encontrarse preparados para poder iniciar reclamaciones o conocer el medio de defender sus derechos ante una falta de conformidad en la adquisición de bienes.

- Cauces de facilitación del ejercicio de derechos para los consumidores: No obstante, se ha ido creando una administración encargada de consumo tanto a nivel municipal como autonómico y estatal. Así, se cuenta con las OMICs (Oficinas Municipales de Información al Consumidor) que ofrecen información y asesoramiento sobre posibles reclamaciones y abusos frente a consumidores. Además, se han establecido por la Administración cauces de solución arbitral de conflictos a través del sello de arbitraje de consumo. Se cuenta con una Administración que tutela a los consumidores en sus intereses y derechos en los actos de consumo.

- Abusos en el pase de la responsabilidad: el consumidor adquiere un bien y se relaciona con su vendedor. Pero por detrás en el circuito comercial se sitúa el proveedor y el fabricante de dicho bien, a quienes no conoce el consumidor y con quienes no ha te- 
nido relación alguna, salvo la compra al vendedor de ese producto. El consumidor es reenviado, muchas veces, a reclamar al fabricante o al proveedor cuando, en realidad, ninguna relación directa se ha establecido con ellos salvo la mediata de adquirir su producto al vendedor. Esta diversa relación comercial empresarial no puede afectar al consumidor, ya que se trata de un obstáculo más en la satisfacción del consumidor.

- Respuestas flexibles ante la falta de conformidad: Frente a un posible defecto en la compra de un bien, se plantea el inicio de una acción judicial como único camino posible a la resolución del problema. Sin embargo, el consumidor necesita soluciones más sencillas y flexibles. Parece que en tal caso, la solución al consumidor pasa por la reparación o sustitución del bien, como fórmula de salida básica del conflicto ante una falta de conformidad. Cuando ya sea imposible el saneamiento del bien y se mantenga la falta de conformidad con el contrato, el comprador consumidor estará en disposición de insistir en la otra forma de saneamiento posible: que se aminore el precio o se proceda a la restitución de las aportaciones realizadas por las partes. En definitiva, la resolución del contrato. Parece que son derechos lógicos derivados de la propia posición que ocupa el consumidor y la necesidad de adecuar los bienes a su conformidad natural y contractual.

- Aseguramiento de la calidad NORMAS ISO: La sociedad está cambiando y en el momento actual cualquier servicio o producto debe contar con una calidad adecuada. Debe existir una conformidad entre el bien y su destino. En nuestra sociedad, se están asentando criterios de calidad en la fabricación y comercialización de productos y las empresas adecuan su funcionamiento a normas de aseguramiento de la calidad denominadas normas ISO. También las empresas que ofrecen productos en el mercado, ofrecen una garantía de los mismos, de uno o dos años, e incluso hasta de cuatro años, según el tipo de producto y fabricante. Se identifica, pues, un binomio de producto y calidad, el cual quiebra cuando se produce una falta de conformidad del bien adquirido con el uso ordinario del mismo o aquello que pudiera esperarse fundadamente de su naturaleza y finalidad.

- Saneamiento de los circuitos comerciales: Dentro de esta tendencia hacia la calidad, el ordenamiento jurídico dispone también normas que tratan de sanear los circuitos comerciales del mercado. Este saneamiento se inicia mediante la concesión a los consumidores de derechos frente a su vendedor para poder reclamar 
el saneamiento del bien que adolece de falta de conformidad o, en su caso, las alternativas de reducción de precio o la resolución del contrato. Este conjunto de derechos del consumidor provocará en el vendedor la mejora de la calidad en el aprovisionamiento de productos. Y así, cuando el vendedor, se vea «salpicado» por reclamaciones de saneamiento en productos con falta de conformidad y cuyas reclamaciones no hayan sido atendidas por su proveedor o fabricante, se alineará con aquellos fabricantes o proveedores que le ofrezcan calidad en sus productos. Y además de calidad, también garantía y servicio en atención de aquellas faltas de conformidad que existieren. De esta manera, el circuito comercial se investirá de calidad y llegará, finalmente, al consumidor un producto, también, de calidad.

- Cauces de resolución alternativa de conflictos: Por último, el consumidor que tope con una negativa fundada o infundada del vendedor respecto de la falta de conformidad, se verá abocado a un procedimiento judicial. Pero aquí también han de buscarse fórmulas alternativas y abiertas de resolución de conflictos que en base a pruebas técnicas dictaminen la razonabilidad de la reclamación y la existencia de falta de conformidad o no del bien con respecto a su uso y demás condiciones relativas a su propia naturaleza. La gestión de estos conflictos ha de profesionalizarse y administrarse por entes especializados que dispongan de peritos técnicos que puedan gestionar adecuadamente el conflicto y arbitrar soluciones alternativas a través de la negociación, la mediación o incluso el arbitraje. También aquí las administraciones y los colectivos empresariales pueden organizar estos cauces de solución alternativa, tal y como sugiere la directiva de la que trae causa la ley.

\section{Introducción}

La Ley 23/2003 incorpora al Derecho Español la Directiva 1999/44/CE, del Parlamento Europeo y del Consejo, sobre determinados aspectos de la venta y garantía de los bienes de consumo.

Esta ley introduce el principio de conformidad de los bienes con el contrato. Se aplica a todos aquellos de contratos de compraventa de bienes de consumo celebrados entre vendedor y consumidor, cuyo desarrollo se contiene más adelante.

Por vendedores entendemos en esta Ley, a las personas físicas o jurídicas que, en el marco de su actividad profesional, venden bienes de 
consumo. Los consumidores serían todos aquellos definidos como tales en la Ley General para la Defensa de los Consumidores y Usuarios de 26/1984, de 19 de julio.

La Ley modifica el régimen del saneamiento por vicios ocultos en la venta de bienes de consumo. Así, existe una regulación propia de las acciones de reparación y sustitución del bien vendido, de rebaja de su precio y de resolución de la compraventa previstas en dicha Ley, las cuales sustituyen, en el ámbito de las compraventas de bienes de consumo, a las acciones redhibitoria y quanti minoris derivadas del saneamiento por vicios ocultos, dejando a salvo las acciones indemnizatorias que asisten a los compradores.

La nueva Ley crea un régimen específico aplicable a los contratos de compraventa civil de bienes de consumo celebrados entre los consumidores y los vendedores profesionales. No hay que olvidar tampoco que aquellas compraventas civiles no comprendidas en el ámbito de la directiva seguirán regulándose por el régimen de saneamiento de vicios ocultos del Código Civil.

De la misma forma, aquellos aspectos de la garantía comercial no recogidos en esta Ley, continúan regulándose en la Ley de Ordenación del Comercio Minorista.

Se dispone, igualmente, de un conjunto de medidas tendentes a garantizar un mínimo uniforme de protección de los consumidores con carácter imperativo. La finalidad es garantizar la conformidad de los bienes en los contratos de compraventa de consumo. Para ello, se articula una serie de derechos del consumidor ante esta falta de conformidad durante un período de dos años a partir de la compra del bien.

También se regulan en la nueva Ley medidas, acciones y otras cuestiones relativas a las garantías comerciales. Pero lo más relevante es la determinación de la falta de conformidad y el juego de las relaciones entre consumidor-vendedor, vendedor-proveedor/fabricante.

Se trata de una Ley que puede asustar al comerciante vendedor ante nuevas exigencias de reparación o de sustitución del bien. Existe una sensación en el empresario vendedor de «víctima», que tendrá que hacer frente a la reclamación de los consumidores y con dificultades para luego repercutir o resarcirse del proveedor/ fabricante.

Ante esta perspectiva, en primer lugar, hemos de señalar que el empresario elige posicionarse en un circuito de calidad de sus productos o en una venta con ausencia de calidad y de servicio. Es decir, que el empresario vendedor elige los productos que oferta a sus clientes, conoce las fuentes de aprovisionamiento del mercado y conoce a sus proveedores. Lo que la Ley pretende es dotar de calidad el circuito comercial, es 
decir trata de sanear el circuito comercial, mediante la concesión de derechos a los consumidores y la facilitación de su reclamación primero frente al vendedor y después de éste en cascada frente al causante de la falta de conformidad. Parece que en definitiva, el vendedor tratará de alinearse con aquellos proveedores que más calidad y garantía le ofrezcan al vendedor $\mathrm{y}$, por ende, al consumidor.

\section{Bienes de consumo}

¿Qué entiende la Ley 23/2003 por bienes de consumo? A los efectos de esta Ley, se consideran bienes de consumo los bienes muebles corporales destinados al consumo privado.

La clave está en reconocer cuáles son esos bienes muebles corporales. La Directiva de la CE 1999/44 define como bien de consumo cualquier bien mueble corpóreo, excepto los bienes vendidos por la autoridad judicial tras un embargo u otro procedimiento, el agua y gas cuando no estén envasados para la venta y la electricidad. La Ley de venta de bienes al consumo se ajusta a lo desarrollado por dicha Directiva, y establece al efecto los mismos parámetros.

En este sentido, el Real Decreto 1507/2000 actualiza los catálogos de productos y servicios de uso y consumo común, ordinario y generalizado y de bienes de naturaleza duradera. A estos efectos, el Real Decreto distingue entre productos y servicios de uso común, ordinario y generalizado y bienes de naturaleza duradera. En los primeros, la clasificación se realiza en atención a productos alimenticios y alimentarios (carnes, pescados, leche...), productos no alimenticios (instrumentos de óptica, fotografía, muebles, artículos para vestido y calzado...) y servicios (sanitarios, de transporte...).

En los segundos, esto es, bienes de naturaleza duradera, la clasificación es más concreta. Forman parte de este tipo de bienes la herramientas, cuchillería y similares, muebles y en general, accesorios y enseres domésticos, aparatos eléctricos, electrónicos e informáticos y similares, vehículos, motociclos...y sus piezas de recambio, juguetes, juegos...

Esto nos lleva a la conclusión de que todo bien corporal mueble, ya sea de uso o consumo común, ya sea bien de naturaleza duradera, entra dentro del concepto de bien de consumo establecido por la Ley 23/2003 de venta de bienes al consumo. Es importante recordar que el destino será el consumo privado, tal y como señala el art. 1 de la Ley, si el destino es otro, no podremos considerar el bien como de bien de consumo. 


\section{Concepto de consumidor en la nueva Ley}

La nueva Ley de Garantías en ventas de consumo al señalar los principios generales repara en los conceptos de vendedor y consumidor. El vendedor, tal y como establece esta Ley, está obligado a entregar al consumidor un bien que sea conforme con el contrato de compraventa en los términos que establece la misma. Son vendedores, por tanto, las personas físicas o jurídicas que, en el marco de su actividad profesional, venden bienes de consumo.

La cuestión se complica cuando se pretende acotar la definición al concepto de consumidor. ¿Qué entendemos por consumidor en esta nueva Ley? Según señala la Ley, se consideran consumidores los definidos como tales en la Ley 26/ 1984, de 19 de julio, con lo que directamente nos remite a la Ley General para la Defensa de los Consumidores y Usuarios.

En este sentido, y siguiendo la LCU, son consumidores o usuarios las personas físicas o jurídicas que adquieren, utilizan o disfrutan, como destinatarios finales, bienes muebles o inmuebles, productos, servicios, actividades o funciones, cualquiera que sea la naturaleza pública o privada, individual o colectiva, de quienes los producen, suministran o expiden (art.1.2..$^{\circ}$.

La misma Ley aclara también que no tendrán la consideración de consumidores o usuarios aquellos que, sin constituirse en destinatarios finales, adquieran, almacenen, utilicen o consuman bienes o servicios con el fin de integrarlos en procesos de producción, transformación, comercialización o prestación a terceros $\left(\operatorname{art} .1 .3 .^{\circ}\right)$. Veamos diferentes supuestos:

-EI consumidor como destinatario final: La expresión «destinatario final» es la equivalente a la del consumidor final, esto es, que adquiere los bienes o servicios para utilizarlos o consumirlos él mismo, y que, en consecuencia, esos bienes o servicios quedan dentro de su ámbito personal, familiar o doméstico, sin que vuelvan a salir al mercado.

$¿$ Y que ocurre con la transmisiones de los bienes adquiridos hechas a familiares o en el ámbito doméstico?, ¿Se puede impedir considerar como destinatario final al adquirente que hace esa transmisión?

La respuesta a estas preguntas y a otras que se planteen al respecto es que las transmisiones o cesiones ajenas al mercado no inciden en la consideración como destinatario final de los bienes o servicios. Es decir, el consumidor será el destinatario final de los bienes o servicios dentro del mercado, pero no será destinatario final si adquiere los bienes o servicios para volver a introducirlos en el mercado. 
-Integración en un proceso de producción de bienes o servicios para el mercado: La referencia al mercado aparece implícita en cierto modo en el término procesos, y más claramente en el término comercialización. Ese destino (el mercado) hace que la actividad en cuestión no pueda considerarse personal, familiar o doméstica, y por ello, el adquirente de un bien o servicio que no lo vuelva a introducir en el mercado, pero lo utilice dentro de un proceso de producción de bienes o servicios para el propio mercado, no tendrá la consideración de consumidor o usuario.

¿Y qué pasa con las pequeñas empresas que adquieren bienes o servicios que van a ser utilizados tanto para fines personales, familiares o domésticos, como para procesos de producción o comercialización? En estos casos, la solución del problema dependerá del derecho que pretenda ejercitarse frente al transmitente y de las circunstancias en que tuvo lugar la operación. Otro criterio utilizado, a estos efectos, es el del uso al que se destine «principalmente» el bien adquirido, y a partir de ahí se le podrá considerar al adquirente como consumidor o no.

Distinto problema se plantea por la utilización de bienes adquiridos no para su integración en procesos empresariales de producción o de comercialización, sino para la realización de actos aislados de producción. En tales casos pueden plantearse dos situaciones diversas: por un lado, que el bien adquirido se utilice para la producción o comercialización de otros bienes o servicios que son los que realmente se ofrecen en el mercado, por otro, que el propio bien adquirido sea objeto de explotación en el mercado, aunque esa explotación no se integre en un proceso empresarial de producción o de comercialización o en una prestación profesional de servicios a terceras personas.

En el primer supuesto que se plantea, la solución sería la establecida por el apartado 3 del art.1 de la LCU (no tendrán la consideración de consumidores y usuarios...), y a partir de ahí habría que atender al supuesto de la doble utilización (privada y empresarial o profesional) de un determinado bien o servicio. En el segundo caso, habría que considerar que el adquirente no es consumidor, y ello porque no es destinatario final en virtud de lo establecido por el art.1 apartado $2 .^{\circ}$.

- Consumidor jurídico y consumidor material: La LCU considera consumidores o usuarios a quienes «adquieran» (consumidor en sentido jurídico), «utilicen o disfruten»(consumidor en sentido material). Las dos condiciones pueden darse en la misma persona, pero a veces no ocurre siempre así. ¿Qué pasa cuando alguien compra un aparato o producto comestible para regalarlo?, el adquirente será distinto a quien utiliza, disfruta o consume el bien en cuestión, pero ambos ten- 
drán la consideración de consumidores a efectos de la LCU. Esto no quiere decir que puedan ejercitar cada uno de ellos todos los derechos que la Ley atribuye a los consumidores, para ello habrá que atender a la regulación legal de cada derecho.

En relación al término «adquisición», no sólo adquiere quien «compra», sino también quién «encarga» o quien «arrienda». Adquisición no sólo se refiere a propiedad del bien, sino a cualquier acto que permita al adquirente obtener la posesión, utilización o disfrute del bien adquirido.

-Objeto de la adquisición, utilización y disfrute: El objeto de la adquisición, utilización o disfrute pueden ser «bienes muebles o inmuebles, productos, servicios, actividades o funciones».

\section{La conformidad de los bienes con el contrato}

\subsection{Principio de conformidad}

Se establece el principio de conformidad en la venta de bienes de consumo con el contrato. Así, se señalan una serie de requisitos cuya concurrencia implica la conformidad del bien al objeto del contrato. Además, se extienden los requisitos de conformidad al momento de la instalación del bien en determinados casos y una serie de excepciones como la falta de conformidad cuando el consumidor haya tenido participación en determinadas circunstancias de hecho respecto del bien.

\subsection{Requisitos de conformidad}

Han de cumplirse todos los requisitos que se expresan en la Ley para que el bien sea conforme con el contrato de adquisición. Estas condiciones de conformidad se determinan en algunos casos por la idoneidad de su uso, bien para su uso ordinario, bien para aquel uso especial aceptado por el vendedor. En otros casos, se trata de adecuar lo ofertado por el vendedor a su cumplimiento por el bien objeto de venta. Nos referimos a supuestos de desajuste entre la muestra o modelo o en la publicidad y declaraciones sobre el citado bien con la calidad y prestaciones fundadamente esperadas del bien en cuestión.

La falta de conformidad debe concurrir en el bien cuando fue objeto de entrega por el vendedor. Por ello, la responsabilidad del vendedor 
deriva de cualquier falta de conformidad que exista en el momento de la entrega del bien. Veamos:

\subsubsection{ADECUACIÓN A LA DESCRIPCIÓN Y CUALIDADES SEÑALADAS POR EL VENDEDOR EN LA MUESTRA O MODELO}

Si el bien no se ajusta a la descripción realizada por el vendedor y no posee las cualidades que se han presentado al consumidor a través de una muestra o modelo, no existe conformidad. Por tanto, nacen los derechos a favor del consumidor.

\subsubsection{APtITUd PARA El USO ORDINARIO DE DESTINO DE LOS BIENES}

Ha de concurrir una aptitud del bien respecto del uso normal al que se destinen dichos bienes. Al extenderse la garantía a dos años desde la adquisición del bien, nos podemos preguntar si aquellos desgastes del bien que respondan a un uso ordinario también son objeto de garantía. A este respecto, parece que la Ley protege los vicios ocultos en la venta de bienes y la extiende hasta el período de dos años desde la compra. El uso y desgaste normal del bien no parece que tenga cobertura dentro del supuesto de vicios ocultos. Sin embargo, la Ley concede una garantía legal de dos años para todos los bienes corporales. Por ello, si algún bien carece de una duración de vida útil de dos años, deberá así indicarlo. De esta manera se podría acoger el vendedor al conocimiento de dicha circunstancia por el comprador y al ser conocida y aceptada exonerarse de la cobertura legal. Esta menor duración debería determinarse por la naturaleza del bien y su duración útil, basada en criterios técnicos y derivados del propio bien. Por ejemplo, la vida útil de las baterías de los teléfonos móviles tienen una duración próxima a los dos años. Si se ha sometido a dicha batería a un uso continuo, puede empezar a fallar y es necesaria su reposición. Con la nueva ley de garantías, se podrá pedir su reparación o sustitución dentro del plazo legal. Por ello, es necesario arbitrar medidas de transparencia en la venta de bienes cuyo desgaste normal se produzca antes de los dos años de garantía legal.

\subsubsection{APTITUD PARA USO ESPECIAL DEMANDADO Y ADMITIDO POR EL VENDEDOR}

Este supuesto se refiere a aquellos bienes que tienen como destino un uso ordinario pero que también son capaces de adaptarse a un uso especialmente requerido por el consumidor y aceptado por el vendedor. 
Se trata de supuestos en los que el comprador comunica al vendedor que quiere ese bien para el destino especial que hemos mencionado y el vendedor le señala que ese bien es apto para dicho uso especial. En esos casos, ha de hacerse realidad el uso especial, entendiendo que si no es posible este uso especial, nos encontramos ante una falta de conformidad al haber sido admitido dicho uso por el vendedor. Este requisito nos traslada al acto o secuencia de venta en la que el vendedor oferta las grandes ventajas del producto que vende, pero cuyas condiciones, quizá, no se cumplen en su totalidad. Existe, pues, un riesgo en el acto de venta, al tratar de incorporar ventajas y usos del bien inapropiadas.

\subsubsection{AdECUACIÓN DE LA CALIDAD Y PRESTACIONES HABITUALES DE UN BIEN A LAS FUNDADAMENTE ESPERADAS DEL MISMO}

El bien debe contener la calidad y las prestaciones habituales de un bien de ese tipo y corresponderse con las que pudiera esperarse fundadamente de dicho bien.

Este apartado se conecta con

- la naturaleza del bien;

- con las declaraciones públicas sobre las características concretas de los bienes hechas por el vendedor, el productor o su representante en particular en la publicidad o el etiquetado. No obstante, puede producirse un desajuste entre la publicidad del fabricante y sus declaraciones públicas con el conocimiento del vendedor respecto del producto. En tales casos, el vendedor no queda obligado por tales declaraciones públicas, si demuestra que desconocía o que no cabía razonablemente esperar que conociera la declaración en cuestión.

Debería de fijarse un estándar de calidad y prestaciones habituales de cada bien. Después habría que valorar esa adecuación entre lo que ofrece el bien y lo que se podía fundadamente esperar.

\subsubsection{EXTENSIÓN DE LA FALTA DE CONFORMIDAD A LA INCORRECTA INSTALACIÓN DEL BIEN}

Se refiere a supuestos en los que la instalación esté incluida en el contrato de compraventa y haya sido realizada por el vendedor directamente o bajo su responsabilidad. También se extiende el supuesto a aquellos casos en los que el consumidor haya realizado la instalación defectuosa pero se deba a un error en las instrucciones de instalación. 
5.2.6. EXCLUSIÓN DE RESPONSABILIDAD DEL VENDEDOR POR FALTAS DE CONFORMIDAD CONOCIDAS (TARAS, DESPERFECTOS) O DERIVADOS DE MATERIALES SUMINISTRADOS POR EL COMPRADOR

Evidentemente, no puede utilizarse esta Ley de Garantías en la Venta de Bienes de Consumo para plantear reclamaciones abusivas. Por ello, cuando el consumidor acepta la compra de bienes en los que es manifiesto un deterioro, defecto o tara, se excluye la responsabilidad del vendedor. El art. 3.3 LGVBC señala que en aquellos casos en los que el bien contenga una falta de conformidad que conociera el comprador o no hubiera podido fundadamente ignorar en el momento de la celebración del contrato queda exonerada de responsabilidad al vendedor en tales supuestos por dicha falta de conformidad. El segundo supuesto de exoneración del vendedor se refiere a aquellos casos en los que el consumidor ha aportado materiales que han sido objeto de instalación por el vendedor. En tales casos, no podría exigir responsabilidad al vendedor por un producto que contiene materiales suministrados por el propio consumidor. Nos referimos al caso de una reparación de carrocería de automóvil en la que el consumidor, con el fin de abaratar el precio de la reparación, acude a un desguace, compra una aleta de su vehículo y se entrega al taller para su instalación.

En estos casos conviene anotar en el tique de venta o factura la tara o falta de conformidad del bien al efecto de evitar una reclamación abusiva por algo recibido a sabiendas de la falta de conformidad que contenía.

La responsabilidad del vendedor se extiende a la falta de conformidad de las mencionadas que existan en el momento de la entrega del bien, y se concede al consumidor el derecho a la reparación del bien, a la sustitución, a la rebaja del precio y a la resolución del contrato.

\section{Derechos del consumidor ante una falta de conformidad}

\subsection{Sistema de primera opción de saneamiento y posterior de reducción de precio o resolución}

El consumidor tiene una doble opción ante una falta de conformidad. En primer lugar, puede optar entre la reparación o sustitución. En caso de que el bien reparado o sustituido siga conteniendo esa falta conformidad, dispondrá de una segunda opción. Así, podrá elegir entre la opción no realizada en primer lugar, esto es, la alternativa a la primera opción de saneamiento. Y entre las variables de esta segunda op- 
ción, también puede optar bien por una reducción de precio, bien por la resolución del contrato. En todos estos casos, se ha de indemnizar al consumidor por los daños y perjuicios ocasionados al consumidor por la falta de conformidad.

Sin embargo, existen ciertos límites a la primera opción de saneamiento. Algunos derivan del desproporcionado coste entre un saneamiento por reparación y el de sustitución. Otros traen su causa en la naturaleza del propio bien, como es el caso de los bienes de segunda mano en los que no cabe la sustitución.

Recordemos que la responsabilidad del vendedor deriva de cualquier falta de conformidad que exista en el momento de la entrega del bien.

Por su parte, la reducción del precio será proporcional a la diferencia existente entre el valor que el bien hubiera tenido en el momento de la entrega, de haber sido conforme con el contrato, y el valor que el bien efectivamente entregado tenía en el momento de dicha entrega.

El consumidor ha de comunicar al vendedor la falta de conformidad y, cuando le comunique la opción elegida, deberá atenerse a ésta.

\subsection{Limitaciones a la opción de saneamiento}

No será posible exigir la reparación o sustitución del bien cuando esta resultare imposible o desproporcionada. La Ley aclara el concepto de desproporcionalidad en atención a que la forma de saneamiento elegida imponga costes al vendedor cuando sea razonables en atención a varios criterios como:

— Valor que tendría el bien si no hubiera falta de conformidad.

- Relevancia de la falta de conformidad.

-Forma de saneamiento alternativa, si pudiera realizarse sin inconvenientes mayores para el consumidor.

Tampoco es posible la sustitución de los bienes como forma de saneamiento en el caso de los bienes de segunda mano.

\subsection{Reglas y condiciones de saneamiento}

El proceso de reparación está muy regulado y cumple una función tuitiva del consumidor, valiéndose de medidas como la reparación gratuita y a realizar en un plazo razonable. De igual manera, se interrumpe el cómputo de los plazos de la garantía legal durante el período de reparación. 
- Gratuidad para el consumidor: esta gratuidad comprende los gastos necesarios para subsanar la falta de conformidad de los bienes y han de incluirse los gastos de envío, así como los costes de mano de obra y materiales.

- Reparación en plazo razonable: la reparación del bien ha de realizarse sin mayores inconvenientes para el consumidor, habida cuenta de la naturaleza de los bienes y de la finalidad que tuvieran para el consumidor, y además en un plazo razonable. En este supuesto cabe pensar en la posibilidad de utilizar un bien de sustitución temporalmente hasta la reparación definitiva del bien adquirido.

- Suspensión del cómputo de plazos de garantía legal: desde que el consumidor ponga el bien a disposición del vendedor hasta su devolución ya reparado se suspende el cómputo de los plazos de la garantía legal. Y, además, se establece una presunción de falta de conformidad de seis meses, posteriores a la entrega del bien reparado, en caso de falta de conformidad con el mismo origen que motivó la reparación.

-Condiciones de sustitución:

- Imposibilidad de sustitución en el caso de bienes de segunda mano: en este supuesto, el consumidor no puede exigir la sustitución de los bienes de segunda mano ni de aquellos bienes no fungibles.

- Suspensión de los plazos: desde el ejercicio de la opción hasta la segunda entrega del bien, se suspenden los plazos como indica el párrafo $2 .^{\circ}$ del art. 9.1.

\section{Nuevo sistema de plazos}

Con la entrada en vigor de la nueva Ley, ha de considerarse el nuevo sistema de plazos para el ejercicio de los derechos que se contienen a favor del consumidor, así como de suspensión e interrupción de los plazos para la determinación de la falta de conformidad. Así, se señalan de manera sinóptica los siguientes plazos:

-(6 meses) Presunción de conformidad del bien en la entrega: En tales casos, se establece que durante los seis meses posteriores a la entrega, las faltas de conformidad que se manifiesten en ese plazo, ya existían cuando la cosa se entregó. Se excepciona esta presunción cuando sea incompatible con la naturaleza del bien o la índole de la falta de conformidad. 
-(2 años) Aparición de la falta de conformidad: se establece un plazo de dos años de responsabilidad del vendedor por las faltas de conformidad que se manifiesten en ese plazo, a contar desde la entrega del bien.

- Posible pacto de plazo menor (al de dos años) pero no inferior a un año en los bienes de segunda mano: para el caso de bienes de segunda mano, el vendedor y el consumidor podrán pactar un plazo menor a los dos años, pero que en ningún caso podrá ser inferior a un año desde la entrega. La entrega se entiende hecha desde el día que figure en la factura o tique de compra o en el albarán de entrega correspondiente, si éste fuera posterior.

-(3 años) Prescripción acción de reclamación: para el ejercicio de los derechos prescritos en la Ley (arts. 1 a 8). El consumidor dispondrá de un plazo de tres años a contar desde la entrega del bien para iniciar las acciones judiciales correspondientes.

-(2 meses) Deber de comunicación del consumidor sobre la falta de conformidad: se establece un plazo de dos meses para que el consumidor comunique al vendedor la falta de conformidad desde que tuvo conocimiento de ella. No obstante, se establece una presunción iuris tantum, es decir, salvo prueba en contrario, en el sentido de que la comunicación del consumidor ha tenido lugar dentro del plazo establecido.

- (1 año) Ejercicio del derecho de repetición del vendedor al proveedor o fabricante: todo ello desde la fecha en la que se completó el saneamiento. El vendedor que hubiera respondido frente al consumidor dispondrá del plazo de un año para repetir del responsable de la falta de conformidad. Son las típicas relaciones entre vendedor y proveedor o incluso entre proveedor y fabricante, hasta que se completara el saneamiento, trasladándose la responsabilidad por la falta de conformidad, finalmente, al fabricante del producto y obviamente podría serlo por un plazo superior a los dos años de la garantía legal.

-Interrupción del plazo: en el caso de reparación o sustitución, se interrumpen los plazos desde que el consumidor ponga a disposición del vendedor el bien, y concluirá con la entrega al consumidor del bien ya reparado. De igual manera, en el caso de reparación durante los seis meses posteriores a la entrega del bien reparado, el vendedor responderá de las faltas de conformidad que motivaron la reparación. Cuando se reproduzcan en el bien defectos del mismo origen que los inicialmente manifestados, se presume que se trata de la misma falta de conformidad. 
Supuesto extremo de juego de los plazos de la Ley de Garantías

Se va a presentar a continuación un caso extremo de aparición de falta de conformidad y el inicio de una reclamación judicial en busca del saneamiento, que finalmente se produce, y la reclamación empresarial entre el vendedor que realizó el saneamiento frente a su proveedor y fabricante.

En principio, puede producirse la aparición de la falta de conformidad en el mes vigésimo tercero dentro del plazo de los dos años de garantía. A esto ha de sumarse la denuncia de dos meses para la comunicación al vendedor de dicha falta de conformidad así como la opción elegida por el consumidor. El consumidor puede ejercitar la acción en el plazo de tres años a contar desde la compra del bien. A esta reclamación judicial el vendedor puede oponerse, lo que deriva en una sentencia. La tramitación ante el Juez de Primera Instancia se dilata un año. Contra la sentencia se interpone recurso de apelación ante la Audiencia Provincial, lo que conlleva otro año más de duración para la resolución del recurso. En nuestro caso, la sentencia firme condena al saneamiento del bien por parte del vendedor. En la ejecución de la sentencia se produce el saneamiento por el vendedor, quien dispone de otro año más para repercutir el saneamiento al proveedor. De la suma de los años y períodos indicados, resulta que en el sexto año podría recibir el fabricante o proveedor una reclamación del vendedor que ha realizado el saneamiento con el propósito de repercutir el costo de saneamiento al proveedor.

\section{Recapitulación}

La Ley de Garantías en la Venta de Bienes de Consumo es una medida legislativa coherente con el devenir de la sociedad y el entorno del mercado único europeo. La Ley es buena en sí misma y presenta medidas de protección útiles y eficaces para los consumidores. Pero el consumidor somos todos, y todos nos beneficiamos de dicha Ley. El nuevo sistema de Garantías en la Venta de Bienes de Consumo influirá decisivamente en la mejora de la calidad y la toma de decisiones empresariales, apostando por aquellos proveedores que ofrezcan más calidad, garantía y servicio.

No obstante, se presentan incógnitas en la aplicación de la Ley por los Tribunales y el papel de las Administraciones, colectivos empresariales y de consumidores para establecer cauces de solución alternativa de conflictos. Es un momento inmejorable para canalizar este tipo de 
reclamaciones en foros de gestión alternativa de conflictos que procuren una solución rápida, eficaz y amistosa.

Esta norma también produce efectos en el lado empresarial, en el que existe una sombra que acecha a aquel que coloque en el mercado productos que adolecen de falta de conformidad. Así, se han de establecer también acuerdos comerciales entre proveedores y vendedores para gestionar adecuadamente el conflicto, caso de que ocurra y ofrecer una solución rápida y adecuada al consumidor por parte del proveedor a través del vendedor.

Por último, desde el punto de vista jurídico se ratifica la existencia, no ya de una dualidad civil o mercantil de los contratos, sino la consideración de esa triple dimensión del saneamiento por vicios ocultos del ámbito mercantil, del ámbito civil y del ámbito de las compraventas civiles de consumo. Esta nueva característica viene a confirmar la conveniencia de contar con una regulación única de obligaciones y contratos que adapte la normativa a las peculiaridades de cada destinatario. 